\title{
Correction to: The Importance of Software in the Electronics Industry of Mexicali. The PLC Case
}

Roberto Carlos Valdés Hernández, Adelaida Figueroa Villanueva, and José Luis Arcos Vega

\section{Correction to:}

Chapter "The Importance of Software in the Electronics Industry of Mexicali. The PLC Case" in:

Y.-D. Zhang et al. (eds.),

Smart Trends in Computing and Communications, Lecture Notes in Networks and Systems 286, https://doi.org/10.1007/978-981-16-4016-2_13

In the original version of the book, the title of Chapter 13 has been changed from "The Innovation in Manufacturing Areas of Electronics Industry of Mexicali Using PLC" to "The importance of software in the electronics industry of Mexicali. The PLC case.".

The erratum chapter and the book have been updated with the change. 